\title{
A URBANIZAÇÃO INDUSTRIAL E O COLAPSO DAS FORMAS
}

\section{Raimundo Nonato Oliveira Furtado}

Professor de História do Centro Federal de Educação Tecnológica da Paraíba - CEFETPB; Mestre em Desenvolvimento Urbano e Meio Ambiente; ntrmnd@netscape.net

Recebido em agosto/2004 e Aceito em dezembro/2004

\section{RESUMO}

O presente trabalho analisa a seqüencialidade construtiva da ordenação humana, enquanto coletivo, e sua causalidade submetida à construção do imaginário social, destacando-se os aspectos relacionais da produção, aglomeração, suburbanização, industrialização e a falta de liberdade do homem moderno. Apresenta, como conseqüência, o desvalor relativizado a que se subordinou o ser humano, em busca do controle das forças da natureza.

Palavras-chave: modernidade; globalização; natureza; espetáculo; cidade.

\section{THE INDUSTRIAL URBANIZATION AND THE COLLAPSE OF THE FORMS}

\begin{abstract}
The present work analyzes the constructive sequenciality of the ordinance human being, while collective, e its causality submitted to the imaginary construction of the social one, being distinguished the relationary aspects of the production, agglomeration, suburbanization, industrialization and the lack of freedom of the modern man. It presents, as consequence, the relativized desvalor the one that if subordinated the human being, in search of the control of the forces of the nature.
\end{abstract}

Key-words: modernity; globalization; nature; spectacle; city. 


\section{A URBANIZAÇÃO INDUSTRIAL E O COLAPSO DAS FORMAS}

Apesar das controvérsias, entre os cientistas sociais, acredita-se que, em algum momento entre os anos 1966 e 1974, o mundo mudou. Deixamos para trás a era moderna e entramos na era pós-moderna, ou na condição de pós-modernidade.

Em The Condition of Postmodernity, David Harvey ${ }^{1}(1990$ : 39) cita Paul Jenkis afirma que "o modernismo terminou e a era pós-moderna começou às 15 h32 (horário padrão), no dia 15 de julho de 1972 em St. Louis, Missouri, com o lançamento do sistema de moradia modernista Pruitt-Igoe" 2 . Desde então muitas coisas aconteceram -desindustrialização, suburbanização, aumento forte na flexibilização do acúmulo de capital-, levando-nos à globalização hoje conhecida.

Alguns componentes atingiram sua maioridade nesse período, como a força reguladora da TV, a proliferação da TV a cabo, do vídeo, do fax, das fórmulas da indústria farmacêutica do "humor", computadores, telefonia celular e Internet. Os ideais de pureza e profundidade nas artes e arquitetura deram lugar à ironia e à manipulação de superfícies. A arte popular de alto e baixo nível parece obscura e indefensável. Até mesmo na filosofia muitos foram levados a abandonar sua fé no fundamentalismo epistemológico e ético. Tudo isso teve impacto sobre nossos pensamentos, desejos, sentimentos.

Num mundo sem um sentido real de lugar, nos tornamos nômades espirituais cínicos e descrentes. Um mundo onde o place marketing - Coca-Cola, McDonald, Hugo Boss, Toyota, Sansung, CNN, Intel, Microsoft, Shell, Mitsubish, Nike, etc. -, determina o consumo e nossas personalidades passam a ter plasticidade, deixando a autenticidade para trás como se esta fosse apenas um engodo.

Referindo-se a obras como América ${ }^{3}(1988)$, e The Gulf War Did Not Take Place ${ }^{4}(1995)$, Jean Baudrillard destaca que atualmente "você é desprovido de toda profundidade [...] uma neutralidade brilhante, móvel, superficial; um desafio ao significado e à profundidade, um desafio à natureza e à cultura, um hiperespaço exterior, sem origem $e$ sem fontes de referência”. É uma deferência a Simulacros e Simulações ${ }^{5}$.

Os seres humanos podem representar o mundo através de sinais, linguagens e imagens. Por essa razão vivemos num mundo de coisas. Porém, os teóricos da pós-modernidade argumentam que vivemos hoje num mundo completamente saturado com representações, tanto lingüísticas como pictóricas. Palavras, sinais e imagens estão por toda parte e usurpam a imediação do mundo material a tal ponto que o mundo que experimentamos é mais bem descrito como um espetáculo do que como um continuum espaço-tempo repleto de objetos físicos.

Em The Society of the Spectacle ${ }^{6}$, Guy Debord (1983 : 5) escreve:

\footnotetext{
${ }^{1}$ Cambridge, MA: Blackwell, $1990: 39$

2 Apresentado neste texto, numa ordenada histórico-temporal, o programa apontava a construção de conjuntos habitacionais que sustentavam a plasticidade moderna e punha fim aos guetos. Seu estabelecimento, marcou, abertamente a segregação racial e o isolamento do negro americano. A resposta foi o apedrejamento das estrutura e por fim a implosão das construções prediais.

${ }^{3}$ Londres: Verso, 1988, pp. 1-13, 66-71, 123-126

${ }^{4}$ Bloomington: Indiana University Press, 1995

${ }^{5}$ Autor: Jean Baudrillard.

${ }^{6}$ Originalmente La Societé du Spectacle (Paris : Éditions Buchet-Castel, 1967).
} 
Em sociedade em que as modernas condições de produção prevalecem, tudo na vida se apresenta como um imenso acúmulo de espetáculos. Tudo o que foi diretamente vivido foi convertido em representações. As imagens destacadas de todo aspecto da vida se fundem num fluxo comum em que a unidade dessa vida não pode mais ser restabelecida. A realidade considerada parcialmente se desenrola, em sua própria unidade geral como pseudo-mundo à parte, um objeto de mera contemplação [...]. $\mathrm{O}$ espetáculo não é uma coletânea de imagens, mas uma relação social entre pessoas, mediadas por imagens.

Tudo gravita em torno da capacidade de produção dos mais diversos tipos de indústria. A forma como essa realidade foi e está moldada alterou toda a idéia da relação cidade-campo. A cidade tornou-se um composto de subúrbios (residencial, industrial, turístico) que apagaram a paisagem cada vez mais longe do centro, e que tende hoje a englobar a totalidade do espaço nacional com a transformação da agricultura em indústria mecanoquímica, que produz para o mercado.

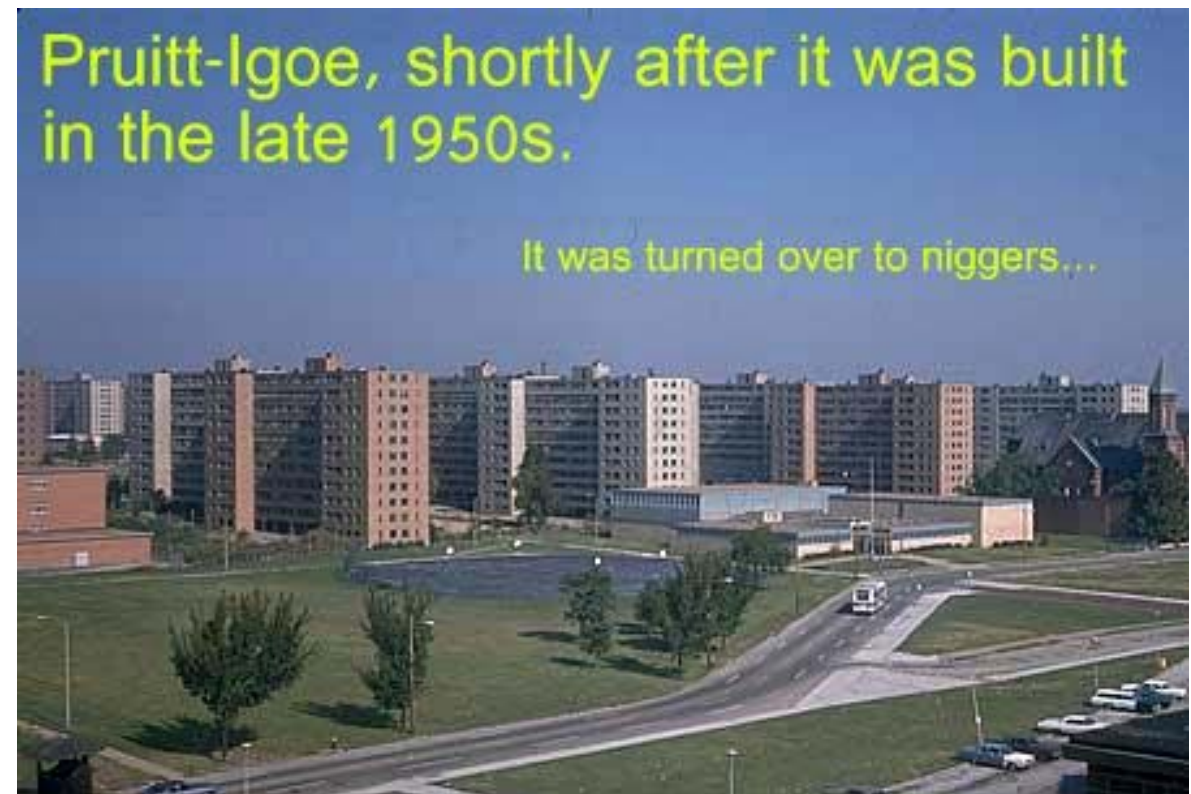

FOTO 1 - Reprinted from Donald MacDonald, Democratic Architecture (1996)

Já não existe campo que não sofra as conseqüências da industrialização - poluição, estandatização dos produtos e dos costumes, concentração e desertificação. CHARBONEAU (1988: 43), referindo-se a determinados espaços europeus, afirma: "já não há aldeia, a escola e a igreja fecharam a espera da auto-estrada, a barragem ou a Disneylândia lhes apaguem os vestígios. Quando estiverem construídos, construir-se-á qualquer outra coisa no lugar. E depois qualquer outra coisa mais..."

Na sua origem, o homem não se distingue da natureza; ambos estão mergulhados no Cosmos. Para o índio na sua forma natural, república, salário e riqueza não fazem nenhum sentido. Para o pagão primitivo não havia natureza, havia apenas deuses: benéficos ou terríveis. A natureza, como a conhecemos hoje, é uma invenção dos tempos modernos. Por possuir, na sua essência, uma força superior a humana, o homem moderno passou a percebê-la como algo a ser "rejeitado". Era preciso, primeiro, lutar, repelir sem trégua a maré verde; era preciso cortar, queimar, ordenar esta coisa sem controle; era preciso, em suma, ordenar o "caos". 
Mas, apesar disso, essa "guerra" guardava em si uma certa forma de respeito. Era um adversário grande, difícil e, por isso, era preciso também cortejá-lo: a ordem das coisas era uma ordem sagrada. O homem que deveria lutar para sobreviver, tremia e temia. Seus rituais marcavam sua conduta e desculpavam-na. Quando alguns mistérios começaram a serem desvendados, Prometeu tentou roubar o fogo do céu, mas foi punido. Hoje, quando Prometeu libertado tornou-se Deus, o indivíduo moderno recorda nostalgicamente a infância perdida. Lembranças do Éden pairam ainda sobre as cortinas de fumaça das sociedades industriais.

Tudo começou a mudar no ano um. Naquilo que Prometeu, o homem-deus, tinha falhado, o Deus-homem obteve êxito. A hora do grande Pã chegara: o Deus cristão o abateu. Com a gênesis, Deus não é mais o Cosmos ao tornar-se, criação de uma pessoa divina. Fez-se a luz desagregando-a da noite - a luz separou-se das trevas: houve dia e noite; a Terra emergiu das águas, Adão foi criado e, apesar de ser pó, tinha a imagem de Deus. Seu corpo podia participar do universo, mas seu espírito pertencia a outro reino -o espírito separa-se da matéria; o pecado -a consciência do bem e do mal não existia-, no Éden, faz o homem vê a si próprio e passa a reconhecer o que Deus conhecia. Deus passou a ser só Deus, as coisas apenas coisas; o homem pode então tocá-las.

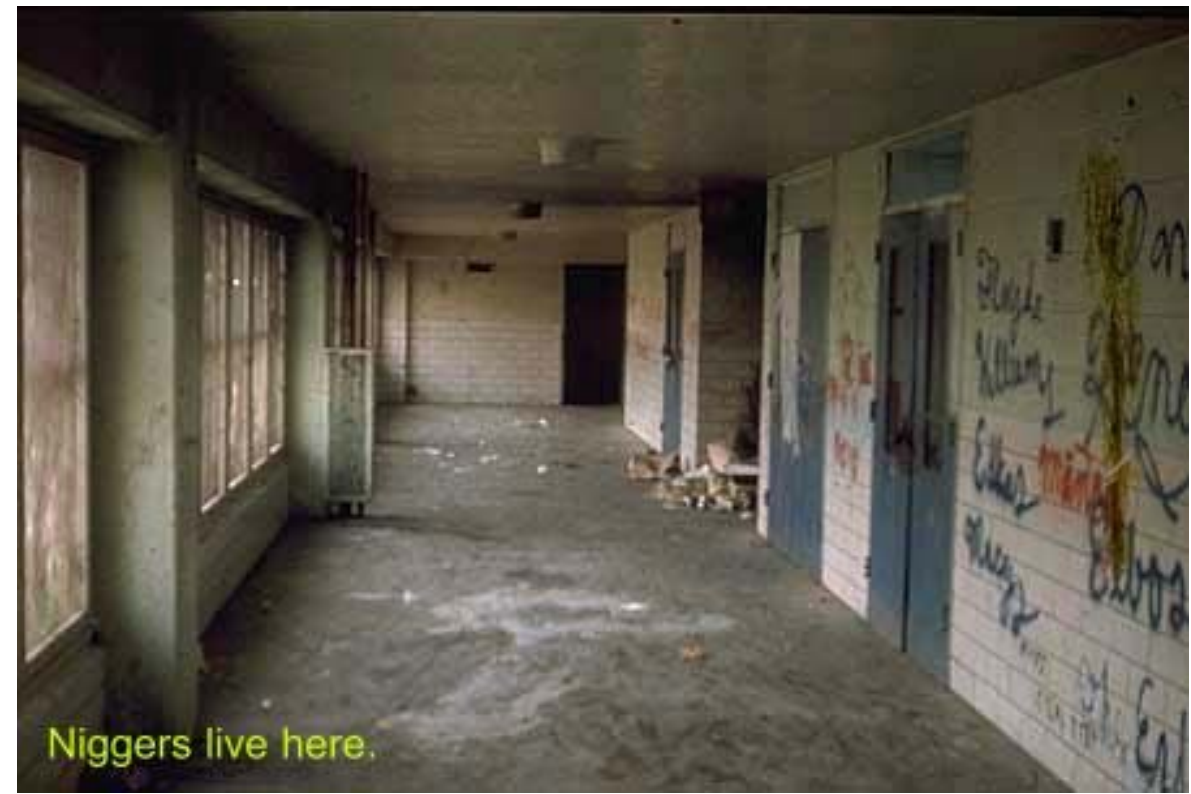

FOTO 2 - Reprinted from Donald MacDonald, Democratic Architecture (1996)

A ordem cósmica podia ter "peso” mas já não possuía autoridade sobre o espírito humano. Tornava-se possível conhecê-la e agir sobre ela. A necessidade passava a ser só necessidade. É isso que nos faz compreender que o Cristianismo da Reforma e da ContraReforma são antievangélico. A Ciência penetrou o mecanismo do Cosmos, e assim a técnica permitiu transformá-lo. O homem, privado da alma, já não encara a si como parte da natureza, como seu pretenso "tutor". Assumindo a posição de confronto, ele estabelece suas conquistas: constrói a gen, a tribo, a micro-sociedade e, finalmente, as sociedades humanas.

A civilização e a construção da cultura é anti-natureza, sobretudo quando o ser se sente fraco ante o adversário. O domínio da natureza, antes do advento das máquinas, é a soma do esforço da luta de vários homens. No ocidente, à porta da casa começava o campo, estabelecendo-se uma restrição e, conseqüentemente, o ordenamento territorial. 
A loucura para organizar o caos primário levou a outro caos maior: a destruição. Assumimos uma posição muito arriscada, nos interessamos pelo solo apenas no preço que pode custar o seu hectare; pelo rio, naquilo que ele pode nos fornecer em quilowatt de energia. A liberdade do homem estava submersa na natureza e desprendeu-se, mas foi dela que saiu. A natureza foi vencida. É por isso que tomamos consciência dela. O combate do homem contra natureza foi muito difícil e incerto, e, mesmo quando a vitória se tornou evidente, o passado não foi de imediato abolido pelo futuro. Quando o etnógrafo, por exemplo, assiste a uma dança primitiva em uma tribo qualquer, com sua câmera de vídeo a mão, também está participando dos mitos e ritos daquele grupo. A natureza subsiste lado a lado com a civilização.

\section{O HOMEM DA SOCIEDADE DA ECONOMIA}

Até a Segunda Guerra Mundial, quando se expandiu a economia e a técnica, as gerações viveram entre duas fronteiras: o campo e a cidade. O camponês imigrado na cidade, o citadino regressando à terra dos pais, construía, sem saber, a "teia" que envolveria tanto o campo quando a cidade no mesmo novelo de espoliação do capitalismo industrial.

A oposição campo vs. cidade, sociedade industrial vs. sociedade sem indústria, é mais profunda do que a oposição de classes. Quem fornece o aperitivo para estas mudanças (princípios e modelos) - os padrões de vida - é a burguesia. No pós-guerra, o campo é um corpo estranho que se suporta melhor ou pior, enquanto se aguarda o momento de eliminálo, brutalmente ou pela técnica. Enquanto isso, o camponês propriamente dito continua a viver para o essencial, à margem quer do pensamento quer da economia. Os marxistaleninistas assimilaram que poderiam incorporar na luta de classes uma integralização campo vs. cidade como povo.

Quando o ocidente começa a perceber o "descolamento" entre a natureza e o espírito humano, a geometria começa a mover-se e, com o tempo, passou a ser o cetro dos monarcas e arquitetos. Os homens podiam associar-se e apertarem-se uns contra os outros nas paredes, para garantir que não haveria feras nem mortes.

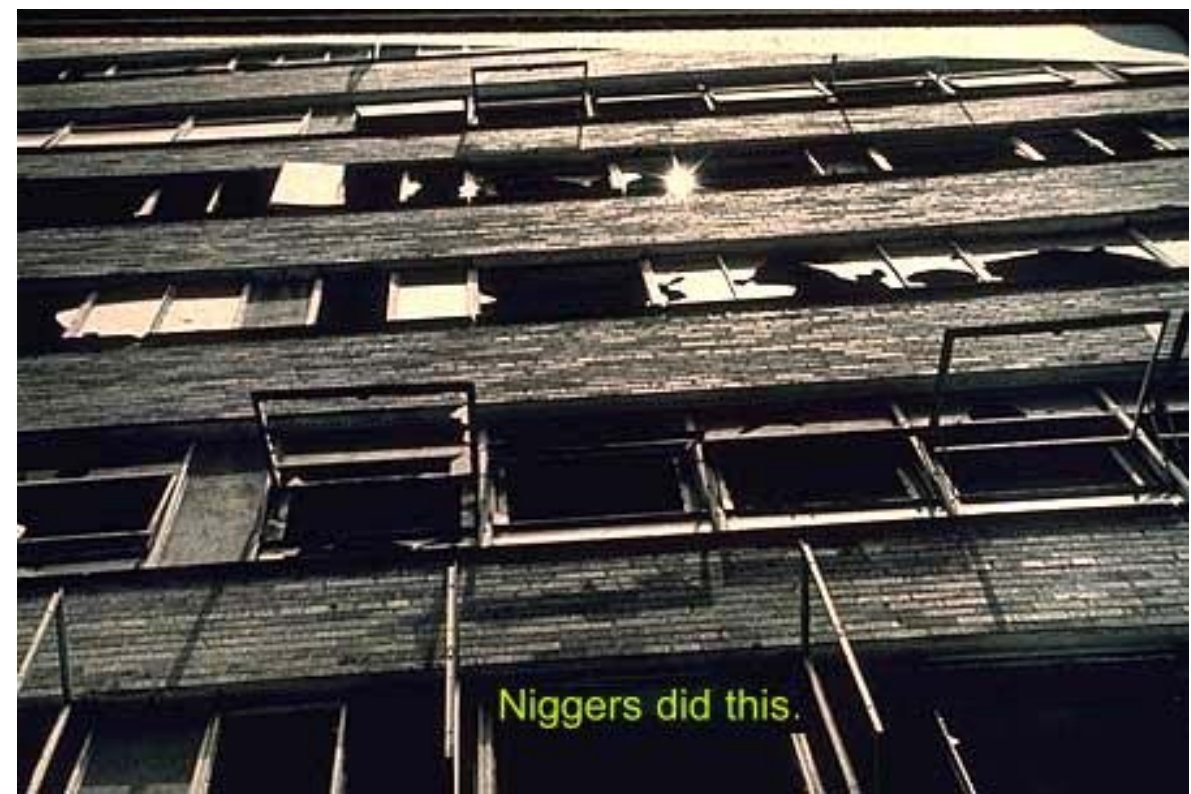

FOTO 3 - Reprinted from Donald MacDonald, Democratic Architecture (1996) 
Nossas cidades são centros econômicos e administrativos, nos quais se enlaçam as malhas das estradas e ferrovias, das relações financeiras e das leis, que encerram o espaço vencido. O campo, por sua vez, fica rodeado pelas cidades e, sem "muralhas" nem vontade de defender-se, com certeza será vencido. A planta dos tentáculos dos nossos subúrbios evoca irresistivelmente a proliferação de um tecido canceroso ao longo de uma rede de veias ou de vasos.

Com o progresso da indústria, as cidades explodiram, projetando ao longe os casebres e as multidões. A cidade da mutação industrial não é nem fruto nem obra, é caos. Homem a homem, casa a casa, as aglomerações se fundem para formar a massa. A aglomeração não tem forma, nem limite, nem estilo, desenvolve-se na desordem que, em sua "imensidão", dá a impressão esmagadora de anarquia. O fato é que ela obedece a determinações implacáveis: preço do terreno, comodidade de transporte, necessidades mais estritas de ordem físico-econômica.

\section{O SUBÚRBIO}

Quando a cidade cresce, algumas modificações ocorrem: o prado transforma-se em terreno baldio; o terreno baldio transforma-se em loteamento; o loteamento transforma-se em blocos de apartamentos, ou seja, a quinta torna-se redes de moradias, tornando-as absurda antes de fazê-las desaparecer; o campo torna-se jardim; a floresta torna-se parque; a sebe vira muro de betão. É a isso que denominamos separação do eu e do tu. Surgindo aqui e ali, a cidade aos poucos vai destruindo o campo, transformando o camponês em operário ou funcionário, a criada em diarista, a sociedade recreativa em discoteca ou boate, o albergue em hotel para turistas. Nesta mutação o que podemos claramente perceber são ruas que têm começo, mas não têm fim; há manifestação da miséria e nela o arrabaldelixeira, o charco, o terreno baldio eriçado de cacos, vasilhas, molas de colchão, garrafas de cerveja, de cachaça ou plásticos de sacolas de supermercados e de refrigerantes pet. Essa produção mecânica que carregamos engordura com pneus e roupas em todos os graus de decomposição. A “zona”, lamaçal onde naufragam todos os destroços tem sua composição: o cântaro furado, o carro velho sem pneus, o desempregado ou a prostituta reformada, o ministro "boliviano" que se tornou alcoólatra, manifesta o "rosto" da estrutura urbana.

É impossível não perceber que a qualidade da estética do subúrbio industrial; é impossível não ver que a sua "grandeza" é profundamente desumana. Reconhecer um subúrbio é analisar a vitória da economia capitalista e a miséria dos indivíduos. Após o desafio vertical, identifica-se uma interminável extensão da mediocridade horizontal em que todas as realidades têm nome de sucursal: o grande supermercado, o cinema, o hospital, etc.

É isso que gente de subúrbio chama de viver em cidade. Esses lugares têm menos vida que em um vilarejo perdido no meio do "nada". Os proprietários constroem suas vivendas: gradeadas com eriçadas pontas de ferro, muros coroados de cacos de vidro; a casota do cão (se é que ele não vive lá dentro da casa junto com os humanos como se fosse gente, pois a imagem superou a realidade e não se distingue mais o que é humano ou animal), pintada de verde; o jardim miniatura - a única alface defendida por toda a família contra a única lesma -; a árvore cuidadosamente podada para que o vizinho não colha a fruta; a obediência aos regulamentos municipais; a construção aqui e ali inacabada. Enfim, a imitação da imitação. Tudo para garantir que em cada interior daquele os móveis sejam da mesma marca que nos demais? A mesma colcha cor de rosa? A mesma revista? 


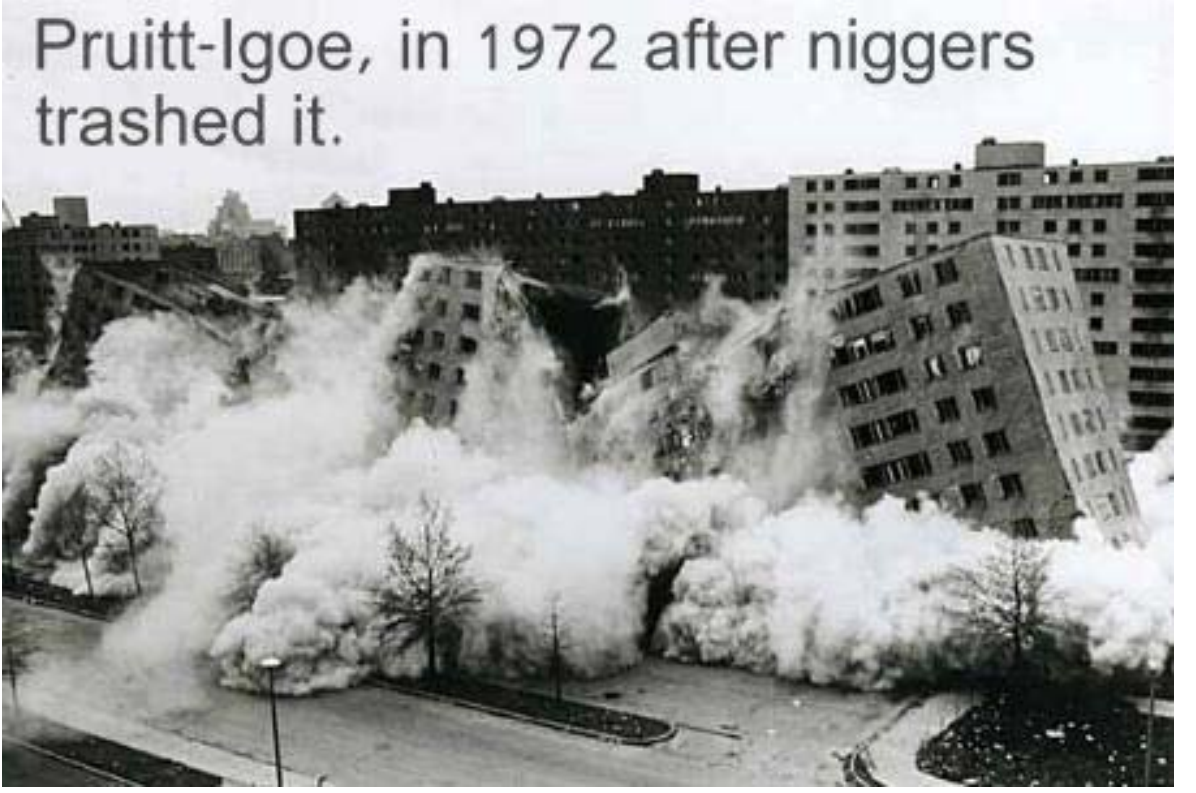

FOTO 4 - Reprinted from Donald MacDonald, Democratic Architecture (1996)

\section{O ISOLAMENTO DO COSMOS}

Os homens juntaram-se na cidade para escapar às forças da natureza. Tiveram êxito excessivo: tornaram-se prisioneiros num meio artificial. Nos campos, o espírito plana no espaço e escolhe a sua presa; por vezes, mesmo cercado de todas as partes do céu, o lugar em que o homem se encontra parece rodeado de infinito, onde se sente verdadeiramente que a terra é apenas um planeta. Na cidade, a alguns metros, os olhos dão na muralha das fachadas: é o céu estreito que parece assediado pelo mundo. No zênite citadino já não existe sol, mas pêndulo de escritório. Como um escravo, o homem carrega no pulso uma algema que só a morte poderá romper: o relógio.

O jardim público, como a praia, por exemplo, não é um prazer, é o medicamento necessário a uma humanidade privada do ar livre; não passa de um fantasma falso: um espetáculo. Saindo da sua casa, o homem ultrapassa a porta para retornar à zona industrial cuja rudeza é mais poética que verdura fabricada para o prazer humano. Na cidade, o homem libertou-se do Cosmos, parece. A morte já não existe, pois se torna um verdadeiro nada. O termo deserto e abismo parecem desprovidos de sentido. Pensa-se que um é horizontal e o outro vertical. A metódica barroca monótona define a cidade: não um sentido, mas uma coisa.

\section{A SOCIEDADE E A LIBERDADE}

A sociedade urbana libertou-se do Cosmos e tornou-se prisioneira de seus muros. Na Idade Média dizia-se que o camponês que queria escapar à servidão deveria fechar-se nos seus muros. O "enlatamento" seria a única forma de impedir o próximo de entrar. O homem livre é o cidadão republicano. A liberdade nasceu na cidade, mas para exercitá-la somos obrigados a deixá-la. A organicidade urbana só funciona segundo um plano estrito e, sabemos muito bem porque sair de férias significa sair da cidade.

Hoje como outrora, a cidade continua a elaborar o único ser capaz de justificá-la, a única força capaz de pô-las em causa - o indivíduo consciente. Como distingui-lo? Pelo olhar. A 
mesma cidade que fabrica este exército de autômatos cultiva os mais requintados tipos humanos. Por isso ela pode ser apresentada como o lugar de uma nova barbárie, ou como um foco de civilização. A cidade é o lugar dos indivíduos, e tudo aquilo que um homem pode encontrar nela a ele se reduz. Se o indivíduo da grande cidade moderna é mais lúcido, mais requintado e intelectualmente mais livre que os tipos humanos que o precedeu, historicamente, isto se explica pela multiplicidade das impressões e pelas mais amplas possibilidades de cultura. Mas essa acuidade da vida interior deve-se ao frêmito interno, a surda queimadura do ser que não está integrado no seu meio. O que matem esta vigilância é o desassossego, a angústia. Sua lucidez nasce do desespero e alimenta-se da inquietação. As estatísticas de loucura e suicídio nas cidades são seus testemunhos.

O indivíduo da cidade existe porque está em conflito com ela: porque o seu desenvolvimento humano está preste a destruir todos os laços sem os quais não pode durar nem crescer. A grande cidade atual conduz a um tipo de sociedade em que se separam ao extremo o pensamento e o comportamento do homem, produzindo seres ainda mais sensíveis, mais inteligentes, que são capazes das evasões mais espantosas no domínio da idéia ou do sonho. Indivíduos cujo pensamento, para sobreviver, tem de produzir uma falsa imagem de uma falsa realidade; "paga-se" o requinte extremo de uma extrema impotência.

Neste ponto, o conflito de que se alimenta a existência da sociedade urbana tem que explodir em plena luz, ou cessar. Ela não pode agravar-se sem provocar o aniquilamento do mais fraco de seus termos. A grande cidade, até a pouco lugar de indivíduos, torna-se, assim, o ambiente que só pode desenvolver-se marginalizando-os ou eliminando-os.

Quando a sociedade urbana procura penetrar o sentido da sua inquietação, já não é para encontrar nela uma vaga nostalgia, mas um perigo que põe em jogo a sua vida e a necessidade da luta pela sobrevivência. A experiência da cidade, levada até o fim, conduz a uma tomada de consciência dos seus problemas; e amanhã eles serão os problemas de todos os homens.

\section{Bibliografia Consultada}

AIA, Randy W. B. The Pruitt-Igoe Project. In:

http://www.churcharchitect.net/article.cfm? article_id=70. (C)2003. Visited in 01/08/2004, time: 01:16h

BRANCO, Samuel Murgel. O Meio Ambiente em debate. - São Paulo : Moderna, 1989

Ecologia da Cidade. - São Paulo : Moderna, 1992

CASTELLS, Manuel. A Questão Urbana. - Rio de Janeiro : Paz e Terra, 1983

DEBORD, Guy. A Sociedade do espetáculo. - Rio de Janeiro : Contraponto, 1997

ENGLETON, Terry. As Ilusões do pós-modernismo. - Rio de Janeiro : Jorge Zahar, 1998

GNU Free Documentation License. In: http://en.wikipedia.org/wiki/Pruitt-Igoe. This page was last modified 03:47, 26 Jul 2004. Visited in 30/07/2004

MORAES, Antonio C. R. Meio Ambiente e Ciências Humanas. - São Paulo : Hucitec, 1997

MARTINE, George (Org.). População. Meio Ambiente e Desenvolvimento:verdades e contradições. - São Paulo :UNICAMP, 1996

NETO, Benedito R. de M. Marx, Taylor, Ford : As forças produtivas em discussão. 2. ed. - São Paulo, 1991

OLIVEIRA, Roberto Cardoso de (et al.). Pós-modernidade. - 5.ed. - Campinas, SP : Editora da UNICAMP, 1995 
SOUZA, Jessé. Patologias da Modernidade: Um diálogo entre Habermas e Weber. São Paulo : Annablume, 1997

Hoffman, Alexander Von. Why They Built the Pruitt-Igoe Project. Joint Center for Housing Studies, Harvard University. In: http://www.soc.iastate.edu/sapp/PruittIgoe.html. Visited in 31/07/2004 